\title{
7. Subjective health, well-being and cognitive capabilities
}

\author{
Miska Simanainen and Annamari \\ Tuulio-Henriksson
}

\section{INTRODUCTION}

The existence of the relationship between poverty and poor health has been known for ages, although the actual mechanisms that connect poverty to health have not been well understood. A growing body of literature indicates that unemployment (which often goes hand in hand with poverty) can pose substantial health risks by negatively affecting, in particular, the mental health, psychological well-being and cognitive capabilities of those who experience it (for example, Acevedo et al., 2020; Wahrendorf et al., 2019; Wanberg, 2012; Pelzer et al., 2014; Van der Noordt et al., 2014; Kim and von dem Knesebeck, 2016). Moreover, we know that the psychological, social and economic dimensions of well-being are strongly interconnected. Unemployment usually leads to a lack of financial resources, and financial resources serve as an important determinant of well-being (Paul and Moser, 2009). Unemployment can also decrease life satisfaction and happiness by means other than income, such as reducing social participation (Kunze and Suppa, 2017). From a practical perspective, whether we can govern the complex relationship between poverty and well-being through a policy action is an important question.

Unconditional cash transfers (UCT) are one potential group of policy instruments for organising social security. UCTs are regular cash transfers that are paid without screening for eligibility and without income-testing or means-testing. Earlier studies have indicated that the introduction of a UCT policy could improve population health. For example, Forget (2011) reports positive results from a Canadian experiment with a guaranteed annual income. Another body of evidence suggests that UCTs may improve some health outcomes in low and middle-income countries, although the relative effectiveness of UCTs and conditional cash transfer programmes (CCT) remains uncertain (for example, Costello et al., 2003; Davala et al., 2015; Pega et al., 2017). 
Assuming the findings from previous studies indicate a causal link between UCTs and better health and well-being, multiple causal mechanisms could be in play depending on the health outcomes measured. For example, increases in household disposable income could be a key explanation for behavioural changes that lead to positive health outcomes, e.g. via better nutrition or increased use of health services. On the other hand, the unconditional nature of UCT payments could potentially reduce income insecurity as reflected in different subjective measures of well-being, such as life satisfaction. Interestingly, in their observational study Zuelke et al. (2018) found that the negative impact of unemployment on depression risk could not be explained solely by differences in material and social resources. The result points to a potential association between benefit type (means-tested versus non-means-tested) and elevated depression risk.

There are only a limited number of empirical studies available covering the effects of UCTs on health and well-being in developed countries. However, in a recent review of studies on instruments similar to UTCs, Gibson et al. (2020) found UCTs could potentially positively affect mental health. In this chapter, we contribute to this mostly unexplored field of research by analysing the health outcomes of a survey study conducted during the Finnish basic income experiment (2017-18), a randomised field experiment with a particular UCT policy called basic income. In the experiment, 2000 unemployed individuals were paid $€ 560$ monthly for two years without income-testing or means-testing and almost without any screening for eligibility. We study how the treatment group (receiving basic income) differs from the control group (not receiving basic income) regarding their subjective health, mental distress, and cognitive capabilities in the end of the experiment. We also reflect on the findings of previous studies on UCTs and basic income and provide a basis for further research on the health outcomes of the Finnish basic income experiment.

The structure of this chapter is as follows. First, we briefly discuss the concept of well-being and the motivation for our multidimensional approach. Second, we describe how the dimensions are operationalised in the survey questionnaire to measure well-being. Thereafter, we present the results and, in the final section, we summarise our findings and discuss their quality and relevance.

\section{MULTIDIMENSIONALITY OF WELL-BEING}

According to the World Health Organization (WHO), health is 'a state of complete physical, mental, and social well-being and not merely the absence of disease or infirmity' (WHO, 2001a). When we ask a person how they perceive their health, the answer represents their own point of view and particular life situation. Two individuals suffering from the same illness may give surpris- 
ingly different answers. For example, individuals with illnesses may evaluate their state of health as very good if they are receiving medical treatment and, as a result, are not facing any major decline in their level of performance.

Well-being is a highly multidimensional concept that can be approached from the point of view of clinical or subjective health, quality of life, or social and economic impact on living conditions, for example. For individuals, self-actualisation, social interaction, happiness, and social capital are all important elements of well-being. Accordingly, the WHO defines mental health as 'a state of well-being in which an individual realizes his or her own abilities, can cope with the normal stresses of life, can work productively, and is able to make a contribution to his or her community' (WHO, 2001b).

During the last few decades, researchers have increasingly shown interest in the subjective dimensions of well-being (for example, Veenhoven, 2004; Layard, 2006). In addition to the objective living conditions and economic resources that individuals need when pursuing their personal goals, subjective perceptions of state of health and life satisfaction are more often being considered relevant indicators of well-being. Yet another line of research concentrates on health-related, social, psychological, and other capabilities of individuals as the core determinants of personal and societal well-being (for example, Sen, 1993).

In our study on the potential effects of the Finnish basic income experiment on health and well-being, we accept the multidimensionality of the concept of well-being and incorporate measures on different dimensions. We explore the potential impact of receiving UTCs on the subjective health, life satisfaction, mental distress, social isolation, and cognitive capabilities of the treatment group. To provide a comprehensive picture of the state of health of the participants, we also investigate the use of health services and the existence of a self-reported, prolonged illness.

\section{DATA AND METHODS}

In the empirical analysis of our study, we utilise data from a telephone survey conducted during the Finnish basic income experiment. In the questionnaire, different dimensions of well-being chosen for the analysis, i.e. subjective health, life satisfaction, mental distress, social isolation, and cognitive capabilities were operationalised with standard question patterns that have been used and validated in earlier studies (for more information on the survey, see Chapter 5).

In the survey, subjective health was measured with the question, 'How would you describe your health generally?' Five response items were available: 'very good', 'good', 'fair', 'poor' and 'very poor'. In addition, state of health was measured with a question about the existence of a long-term 
illness, impairment, or mental health issue that complicates the daily life of the respondent. The existence and the level of impediment caused by the disease was evaluated with response categories 'yes', 'very much so', 'yes, to some extent' and 'no'. We mapped the use of health services by separately asking the number of visits respondents made to a public health care nurse or physician, hospital physician, dentist, or other health care provider.

General life satisfaction was evaluated on a scale from zero ('extremely dissatisfied') to ten ('extremely satisfied'). This particular survey question has also been used in the European Social Survey (ESS, 2018).

Mental distress was evaluated using the five-item Mental Health Index (MHI-5) (Berwick et al., 1991). The index's five distinct questions focus on respondents' subjective mental state during the past month. The dimensions of mental well-being evaluated include nervousness, inability to cheer up, calmness, melancholy, and happiness. Subjective feelings were measured on a six-item scale: 'all the time', 'most of the time', 'much of the time', 'some of the time', 'rarely' and 'not at all'.

The survey also included two distinct screening questions for depression. In the first, respondents were asked if, over the last 12 months, they had experienced a period of at least two weeks during which they were predominantly sad, downcast or depressed. In the second, respondents was asked if they had experienced a period during which they predominantly lacked interest in most of the things that usually bring them enjoyment, such as hobbies, work or other. The evaluation was based on a dichotomous scale with values 'yes' or 'no'. In previous studies, these questions were shown to reliably screen for clinical depression (Arroll et al., 2003).

Social aspects of well-being were surveyed by asking how often the respondents felt lonely ('never', 'very rarely', 'sometimes', 'quite often', 'all the time'). The last dimension of well-being analysed in the study concerned the cognitive capabilities of the respondents. They were asked to describe their recent experiences with memory, concentration, and the ability to learn new things (cp. Troyer and Rich, 2002). The evaluation was based on a five-item scale with the values 'very good', 'good', 'satisfactory', 'poor', 'very poor' (and 'cannot say').

We analysed the survey data by comparing the distributions and summary statistics of the responses of the treatment and control groups. The analysis of group differences was complemented by calculating appropriate tests of statistical significance (t-test and chi-squared test) and interpreted at 5\% significance level. To make the analysis more robust, a logistic regression model was estimated for the study variable on mental distress (MHI-5 index). The regression analysis was performed with two model specifications. The first model included treatment indicator, age and gender as explanatory variables, 
while the second model also included indicators of employment status during the experiment and of respondents' health.

Employment status was inferred from the survey question 'How did you find the jobs you have had since the beginning of 2017?' If a respondent provided an answer to the question ('responded to a job advertisement', 'contacted an employer directly', 'received a referral from the employment office') they were given a positive indicator value for being employed during the experiment. The interpretation of the positive indicator value is that the respondent had at least some work since the beginning of the experiment. Health status, on the other hand, was measured with the previously described study question, 'Do you have a long-term illness, impairment, or mental health issue that complicates your daily life?'

In most cases, we report the results for different study variables as response distributions. Response categories were combined where relevant. In the telephone interview, a 'cannot say' option was offered to respondents with each survey question. A relatively small number of respondents chose this answer, varying from 0.0 percent to 7.0 percent for the questions analysed here. It is not meaningful to include the 'cannot say' answers in the outcome variable on mental distress (MHI index) and so we have omitted them from the regressions. The data were analysed with the $\mathrm{R}$ programming tool.

\section{RESULTS}

\section{Health, Use of Health Services, and Life Satisfaction}

In the treatment group, 58.5 percent evaluated their state of health as good or very good. In the control group, the proportion was 51.4 percent. Those who evaluated their health status as moderate constituted a relatively larger proportion in the control group (32.1 percent) than in the treatment group (27.9 percent). In the treatment group, 13.4 percent considered their health poor or very poor compared with 16.0 percent in the control group. The differences between the groups were almost statistically significant, and the biggest difference in percentage points was observed among those who reported good or very good state of health (Table 7.1, A).

Compared with the treatment group, a larger proportion of the control group reported having a disease, disability or mental disorder that caused hindrance to daily life (Table 7.1, B). In the treatment group, more than half did not report any disease, disability or mental disorder.

Table 7.1 (C) also reports visits to health care services by the treatment and control groups. The differences between the groups are not statistically significant. Both in the treatment and control group, some 40 percent visited a nurse or public health care physician three or more times during the previous 
two years. In both groups, over three quarters had visited a hospital physician or used other health services fewer than three times in the same period. Respectively, almost three quarters had visited a dentist no more than twice.

In addition to the subjective state of health and the use of health services, a measure of life satisfaction was included in the survey. The average value of life satisfaction on a scale from zero to ten was 7.3 for the treatment group and 6.8 for the control group (t-test, $p<0.001$ ). Approximately 1 percent of the treatment group were extremely dissatisfied with their lives, while in the control group, the proportion was about 2 percent. In the treatment group, over 9 percent were extremely satisfied with their lives, compared with 7 percent in the control group. The difference between the group averages was statistically significant.

\section{Mental Distress, Depressive Symptoms and Social Isolation}

Table 7.2 reports the response distributions of separate questions (A.1-A.5) of the MHI-5 index that measures mental distress. Persons in the treatment group reported feeling sad and downcast less often than those in the control group (A.4). In addition, the treatment group reported a higher level of ability to cheer up than the control group (A.2). For other individual questions, we observed no statistically significant differences between the groups. In the treatment group, a greater proportion reported being happy most or all of the time than in the control group, although neither difference was statistically significant.

The MHI-5 index is formed by rescaling the sum of the five separate responses (from 5-30 to 0-100). A dichotomous measurement for clinically significant mental distress was formed using a threshold of 52 points. Respondents who receive no more than 52 points are classified as having clinical mental distress. In the study, we classified persons in the treatment and control groups according to the criteria. Based on this measure, 17 percent of the treatment group and 24 percent of the control group suffered from clinically significant mental distress (A.6).

According to the responses to the screening questions for depression, about one third of the control group reported experiencing depression during the previous year that lasted at least two weeks. In the treatment group, the proportion was approximately one fifth. In addition, more than one third of the control group reported experiencing a period of at least two weeks during which their ability to enjoy or find interest in their usual pursuits declined significantly. In the treatment group, approximately one quarter reported similar experiences. (Table 7.2, B.1-B.2)

Social isolation provides yet another measure of well-being or, more correctly, a dimension of well-being that is both affected by other dimensions 
Table 7.1 Response distributions of survey questions on (A) self-evaluated state of health; (B) existence and level of impediment of a disease, disability or mental disorder; and (C) usage of health services during the previous two years

\begin{tabular}{|c|c|c|c|}
\hline & $\begin{array}{l}\text { Treatment group, } \\
N=586\end{array}$ & $\begin{array}{l}\text { Control group, } \\
N=1047\end{array}$ & $\begin{array}{l}\chi^{2} \text {-test, } \\
p \text {-value }\end{array}$ \\
\hline (A) State of health & & & 0.051 \\
\hline Very good & $16.3 \%$ & $11.4 \%$ & \\
\hline Good & $42.2 \%$ & $40.0 \%$ & \\
\hline Moderate & $27.9 \%$ & $32.1 \%$ & \\
\hline Poor & $9.5 \%$ & $12.3 \%$ & \\
\hline Very poor & $3.9 \%$ & $3.7 \%$ & \\
\hline Cannot say & $0.4 \%$ & $0.3 \%$ & \\
\hline (B) Do you have a disease, disability or mental & & & 0.026 \\
\hline \multicolumn{4}{|l|}{ disorder that hinders daily life? } \\
\hline Yes, with significant hindrance & $13.3 \%$ & $14.9 \%$ & \\
\hline Yes, with some hindrance & $31.6 \%$ & $37.5 \%$ & \\
\hline No & $55.1 \%$ & $47.7 \%$ & \\
\hline (C.1) Visits to public health care nurse & & & 0.070 \\
\hline $0-2$ times & $52.2 \%$ & $51.6 \%$ & \\
\hline$\geq 3$ times & $40.7 \%$ & $43.4 \%$ & \\
\hline Cannot say & $7.1 \%$ & $5.1 \%$ & \\
\hline (C.2) Visits to public health care physician & & & 0.744 \\
\hline $0-2$ times & $56.8 \%$ & $56.6 \%$ & \\
\hline
\end{tabular}




\begin{tabular}{|c|c|c|c|}
\hline & $\begin{array}{l}\text { Treatment group, } \\
N=586\end{array}$ & $\begin{array}{l}\text { Control group, } \\
N=1047\end{array}$ & $\begin{array}{l}\chi^{2} \text {-test, } \\
p \text {-value }\end{array}$ \\
\hline$\geq 3$ times & $38.7 \%$ & $40.4 \%$ & \\
\hline Cannot say & $4.5 \%$ & $3.0 \%$ & \\
\hline (C.3) Visits to hospital physician & & & 0.616 \\
\hline $0-2$ times & $78.2 \%$ & $76.9 \%$ & \\
\hline$\geq 3$ times & $18.1 \%$ & $21.1 \%$ & \\
\hline Cannot say & $3.7 \%$ & $2.9 \%$ & \\
\hline (C.4) Visits to dentist & & & 0.385 \\
\hline $0-2$ times & $72.8 \%$ & $69.8 \%$ & \\
\hline$\geq 3$ times & $25.3 \%$ & $29.0 \%$ & \\
\hline Cannot say & $1.9 \%$ & $1.2 \%$ & \\
\hline (C.5) Visits to other health care services & & & 0.607 \\
\hline $0-2$ times & $72.9 \%$ & $73.7 \%$ & \\
\hline$\geq 3$ times & $22.9 \%$ & $23.5 \%$ & \\
\hline Cannot say & $4.1 \%$ & $2.9 \%$ & \\
\hline
\end{tabular}

of well-being (e.g. mental distress) and a contributing factor itself (the effect of loneliness on mental well-being) (for example, Beutel et al., 2017). The persons in the treatment group reported experiencing less loneliness than those in the control group. The difference was statistically significant (Table 7.2, C). However, in both groups, experiences of continuous loneliness were rare, and over half rarely or never experienced loneliness.

\section{Memory, Learning and Ability to Concentrate}

Cognitive capabilities may serve as important mediators of the impact of a UCTs on the well-being of individuals and on their ability to improve their 
Table 7.2 Response distributions of survey questions on (A) mental distress (individual MHI-5 items and clinically significant mental distress); (B) experiences of depression and inability to enjoy or be interested in things during the previous year; and $(C)$ experiences of loneliness

\begin{tabular}{lllc}
\hline & $\begin{array}{c}\text { Treatment group, } \\
N=586\end{array}$ & $\begin{array}{l}\text { Control group, } \\
N=1047\end{array}$ & $\begin{array}{c}\chi^{2} \text {-test, } \\
p \text {-value }\end{array}$ \\
\hline (A.1) I have been very nervous over the last 4 weeks & & \\
All the time & $1.8 \%$ & $2.3 \%$ \\
Most of the time & $3.6 \%$ & $6.1 \%$ \\
Much of the time & $7.5 \%$ & $9.0 \%$ \\
Some of the time & $22.2 \%$ & $25.0 \%$ \\
Rarely & $36.8 \%$ & $34.9 \%$ \\
Not at all & $27.5 \%$ & $22.1 \%$ \\
Cannot say & $0.5 \%$ & $0.6 \%$
\end{tabular}

(A.2) I felt so low that nothing could make me feel 0.003 better over the last 4 weeks

$\begin{array}{lcc}\text { All the time } & 1.1 \% & 0.9 \% \\ \text { Most of the time } & 1.9 \% & 4.5 \% \\ \text { Much of the time } & 4.2 \% & 5.9 \% \\ \text { Some of the time } & 12.2 \% & 14.2 \% \\ \text { Rarely } & 19.1 \% & 22.4 \% \\ \text { Not at all } & 60.4 \% & 48.5 \% \\ \text { Cannot say } & 1.2 \% & 1.5 \%\end{array}$




\begin{tabular}{llll}
\hline & $\begin{array}{l}\text { Treatment group, } \\
N=586\end{array}$ & $\begin{array}{l}\text { Control group, } \\
N=1047\end{array}$ & $\begin{array}{c}\chi^{2} \text {-test, } \\
\text {-value }\end{array}$ \\
\hline All the time & $13.4 \%$ & $10.8 \%$ & $40.6 \%$ \\
Most of the time & $42.2 \%$ & $15.0 \%$ \\
Much of the time & $16.2 \%$ & $17.4 \%$ \\
Some of the time & $17.2 \%$ & $11.4 \%$ \\
Rarely & $7.6 \%$ & $4.2 \%$ \\
Not at all & $2.6 \%$ & $0.6 \%$
\end{tabular}

(A.4) I felt sad and downcast over the last 4 weeks

$\begin{array}{lcc}\text { All the time } & 1.5 \% & 2.9 \% \\ \text { Most of the time } & 3.4 \% & 5.1 \% \\ \text { Much of the time } & 6.7 \% & 7.5 \% \\ \text { Some of the time } & 15.2 \% & 21.0 \% \\ \text { Rarely } & 28.2 \% & 29.8 \% \\ \text { Not at all } & 42.7 \% & 31.4 \% \\ \text { Cannot say } & 2.3 \% & 2.3 \%\end{array}$

All the time

Most of the time

Much of the time

Some of the time
$14.3 \%$

$10.1 \%$

$36.9 \%$

$33.7 \%$

$16.5 \%$

$16.7 \%$

$16.7 \%$

$20.2 \%$ 


\begin{tabular}{|c|c|c|c|}
\hline & $\begin{array}{l}\text { Treatment group, } \\
N=586\end{array}$ & $\begin{array}{l}\text { Control group, } \\
N=1047\end{array}$ & $\begin{array}{l}\chi^{2} \text {-test, } \\
p \text {-value }\end{array}$ \\
\hline Rarely & $10.4 \%$ & $12.3 \%$ & \\
\hline Not at all & $3.6 \%$ & $5.8 \%$ & \\
\hline Cannot say & $1.6 \%$ & $1.2 \%$ & \\
\hline (A.6) Clinical mental distress (based on MHI-5) & $16.5 \%$ & $24.0 \%$ & 0.001 \\
\hline (B.1) I have experienced depression & & & $<0.001$ \\
\hline Yes & $22.3 \%$ & $32.4 \%$ & \\
\hline No & $76.3 \%$ & $65.0 \%$ & \\
\hline Cannot say & $1.5 \%$ & $2.5 \%$ & \\
\hline (B.2) I have experienced an inability to enjoy & & & $<0.001$ \\
\hline Yes & $24.4 \%$ & $35.9 \%$ & \\
\hline No & $72.3 \%$ & $62.4 \%$ & \\
\hline Cannot say & $3.3 \%$ & $1.8 \%$ & \\
\hline (C) I experience loneliness & & & 0.032 \\
\hline Never or rarely & $58.7 \%$ & $51.3 \%$ & \\
\hline Sometimes or pretty often & $38.6 \%$ & $44.2 \%$ & \\
\hline All the time & $2.3 \%$ & $4.4 \%$ & \\
\hline Cannot say & $0.5 \%$ & $0.1 \%$ & \\
\hline
\end{tabular}

personal living conditions. For example, Mullainathan and Shafir (2013) discuss the process of cognitive 'bandwidth scarcity', where lack of resources impedes sound decision-making and potentially results in negative health 
outcomes. Earlier empirical case studies (Forget, 2011; Pega et al., 2017; Zuelke et al., 2018; Gibson et al., 2020) motivated us to ask if cognitive bandwidth scarcity could be tackled, at least in part, with a UCT policy. CCTs and especially means-tested benefit schemes may cause confusion through poorly understood and complex eligibility and payment rules and welfare sanctions that potentially create new difficulties in the daily lives of benefit recipients. UCTs on the other hand, should provide foreseeable income security via regular, non-means-tested and non-tapered monthly payments.

We found statistically significant differences between the treatment and control groups for all three self-evaluative survey questions concerning cognitive capabilities (Table 7.3). The treatment group evaluated memory functioning, learning new things, and ability to concentrate more positively than the control group. In both groups, less than 10 percent reported having poor or very poor capabilities. The results on cognitive capabilities are in line with the treatment group's consistent outperformance of the control group on different dimensions of well-being.

\section{Sensitivity of the Results: Unemployment and Mental Distress}

A growing body of literature indicates that unemployment poses a substantial health risk to individuals by negatively affecting their mental health, psychological well-being, and cognitive capabilities (for more, see Acevedo et al., 2020; Wanberg, 2012; Kim and von dem Knesebeck, 2016). Wahrendorf et al. (2019) conclude that adverse employment histories are associated with poor subsequent health functioning. A systematic review by Van der Noordt et al. (2014) demonstrates that employment is beneficial for health, particularly in terms of depression and general mental health. Moreover, Pelzer et al.'s (2014) findings suggest that depressive syndromes result from, rather than cause, unemployment. In general, unemployment is linked to decreased subjective well-being (Brown et al., 2003).

We were motivated to control for employment status by the evidence of association and potential causal relationship between employment status and mental well-being shown in the above-mentioned studies. A register study showed only a slight employment effect in the Finnish experiment (Hämäläinen et al., 2020). However, the high non-response rate of the survey study raises doubts about the balance of the study groups regarding relevant covariates of mental health. To analyse the sensitivity of the presented results for potential over-representation of employed and healthier participants, we regress clinically significant mental distress over the treatment indicator and take employment and the existence of a long-term health impediment as additional controls. We assume that the existence of a long-term health impediment 
Table 7.3 Response distributions of survey questions on memory functioning, ability to learn new things, and ability to concentrate

\begin{tabular}{|c|c|c|c|}
\hline & Treatment group, $N=586$ & Control group, $N=1047$ & $\begin{array}{l}\chi^{2} \text {-test, } \\
p \text {-value }\end{array}$ \\
\hline Memory & & & 0.001 \\
\hline Very good & $22.0 \%$ & $16.1 \%$ & \\
\hline Good & $48.8 \%$ & $46.1 \%$ & \\
\hline Satisfactory & $21.9 \%$ & $28.3 \%$ & \\
\hline Poor & $5.8 \%$ & $7.7 \%$ & \\
\hline Very poor & $0.9 \%$ & $1.8 \%$ & \\
\hline Cannot say & $0.6 \%$ & $0.0 \%$ & \\
\hline Learning & & & $<0.001$ \\
\hline Very good & $23.8 \%$ & $16.7 \%$ & \\
\hline Good & $49.8 \%$ & $46.2 \%$ & \\
\hline Satisfactory & $20.7 \%$ & $27.1 \%$ & \\
\hline Poor & $4.2 \%$ & $7.7 \%$ & \\
\hline Very poor & $0.5 \%$ & $1.8 \%$ & \\
\hline Cannot say & $0.9 \%$ & $0.4 \%$ & \\
\hline Ability to concentrate & & & $<0.001$ \\
\hline Very good & $16.1 \%$ & $10.3 \%$ & \\
\hline Good & $51.9 \%$ & $47.4 \%$ & \\
\hline Satisfactory & $24.3 \%$ & $29.6 \%$ & \\
\hline
\end{tabular}




\begin{tabular}{llll}
\hline & Treatment group, $N=586$ & Control group, $N=1047$ & $\begin{array}{c}\chi^{2} \text {-test, } \\
p \text {-value }\end{array}$ \\
\hline Poor & $6.4 \%$ & $9.4 \%$ & \\
Very poor & $1.1 \%$ & $3.2 \%$ \\
Cannot say & $0.1 \%$ & $0.2 \%$ \\
\hline
\end{tabular}

Table 7.4 Regression results on clinically significant mental distress

\begin{tabular}{llll}
\hline & $\begin{array}{l}\text { Coefficient } \\
\text { (basic income) }\end{array}$ & $p$-value & Odds ratio \\
\hline Clinically significant mental distress & & & \\
model 1 & -0.47 & 0.0014 & 0.63 \\
model 2 & -0.34 & 0.0297 & 0.71 \\
\hline
\end{tabular}

Note: In model 1, explanatory variables include the treatment indicator (receiving basic income), age and gender. In model 2, the existence of a long-term disease and employment status are also controlled.

is not affected by participation in the experiment. However, we consider the effect of the health status on subjective well-being plausible.

We tested the stability of the observed difference in mental distress between the treatment and control groups using two logistic regression models. The explanatory variables in the first model included the treatment indicator, age at the beginning of the experiment (age groups 25-34, 35-44 and 45-59 years). The second model also included the state of health (existence of a long-term disease) and employment (being employed during the experiment). In both models, a statistically significant coefficient was estimated for the treatment indicator (receiving basic income) (Table 7.4).

\section{DISCUSSION AND CONCLUSIONS}

In this article, we analysed the self-reported evaluations of participants in the Finnish basic income experiment regarding their state of health, use of health care services, mental distress, and cognitive capabilities. The treatment group receiving basic income reported higher life satisfaction, better health, less mental distress and depression, and stronger cognitive capabilities regarding memory, ability to learn new things, and ability to concentrate than the control group not receiving a basic income. Health and employment status were relevant explanatory factors for the difference in mental distress observed in the data. However, the difference between the treatment and control group 
remained statistically significant even when employment status and health were controlled.

It seems possible that receiving basic income partially reduced the treatment group's economic difficulties and feelings of insecurity caused by unemployment. As a result, this may have increased the mental well-being of the treatment group relative to the control group. An improvement in the perceptions of economic security may have empowered the treatment group in coping with the challenges of daily lives and provided a better sense of direction in life. On the other hand, the analysis showed that employment was a relevant explanatory factor for the differences in mental distress between the groups. It is important to note that, in the experiment, basic income payments also worked as earnings supplements. Relatively greater mental well-being in the treatment group may have resulted from the additional economic resources the experiment provided for those who found a job during the two-year follow-up period.

The results regarding health outcomes are in line with previous studies indicating a positive association between UCT reforms and better mental well-being, although most existing evidence comes from developing countries (for example, Ruckert et al., 2018). In addition to complementing the body of evidence on mental distress, our study provides new and interesting evidence on the association between receiving basic income and improved cognitive capabilities in the context of developed countries. Individuals' cognitive capabilities play a vital role in present-day information societies. Scarcity of cognitive resources impedes sound decision-making, and this hindrance may have a negative effect on health outcomes (Mullainathan and Shafir, 2013). Policy actions that could potentially reduce bandwidth scarcity are worth further analysis and experimentation.

From the Canadian MININCOME field experiment, Forget (2011) reports a reduction of 8.5 percent in the hospitalisation rate of treatment group relative to control group for accidents and injuries and mental health. Their study also found that treatment group's contacts with physicians declined, especially for mental health. In their systematic review of UCT studies in low and middle-income countries Pega et al. (2017) found that UCTs did not increase the use of health services but did potentially improve some health outcomes. However, the evidence on the relative effectiveness of UCTs and CCTs remains very uncertain (Pega et al., 2017).

In our analysis, the use of health services does not differ between the treatment and control groups, but the analysis of subjective health outcomes indicates a potentially positive effect of basic income. In order to find stronger evidence on the potential effects of the Finnish experiment on health behaviour and health outcomes, a register study covering all the subjects of the experiment should be conducted. 
It is worth noting that, based on survey data, both the treatment and the control groups used health care services quite rarely. Similarly, a register study by Lappalainen et al. (2018) found that long-term unemployed individuals use health care services infrequently. The result is societally relevant considering that some half of the individuals in the target group had a prolonged disease causing hindrance in their daily lives.

This study has several limitations that need to be taken into account when interpreting the results. First, the definition of well-being we use concentrates mostly on psychological aspects, ignoring social and economic dimensions. We did, however, control for employment status in our analysis of mental distress. The results of the modelling exercise verified the relevance of employment in explaining mental well-being. On the other hand, even when employment was controlled, a positive association between participation in a UCT experiment and mental well-being was observed.

Second, the data used in the analysis included answers from only 31 percent of participants that were contacted. In the sample of the control group, the response rate was roughly 20 percent. Low and unbalanced response rates raise possibilities of selection bias in the comparisons. We have tried to correct for the possible unrepresentativeness of the samples by weighing the data. However, the results should still be evaluated with caution, and we should avoid any causal conclusions. It is possible that our results indicating higher levels of psychological well-being in the treatment group can be explained by differences between the groups that could not be controlled in the analysis. Here again, a further register study on the Finnish experiment is essential for filling in the knowledge gaps.

In sum, the participants in the basic income experiment receiving a UCT seemed to feel mentally better than those who remained in the existing tax-benefit framework. The treatment group reported less mental distress, depression, downcast, or loneliness than the control group. In addition, the treatment group experienced higher level cognitive capabilities than the control group. The differences were consistently observed when comparing the response distributions of the groups on several different survey measures. The evidence suggests that a UCT policy could help improve beneficiaries' mental well-being, possibly by providing a greater control over their lives in and out of work. Looking ahead, further research on the health outcomes of the Finnish experiment, utilising both administrative registers and survey data, will deepen our understanding of the potential of a UCT programme for improving health outcomes. It will also, we hope, shed light on the complex mechanisms that connect UCTs to the health and well-being of the beneficiaries in a developed welfare state. 


\section{REFERENCES}

Acevedo, P., Mora-Urda, A. I. and Montero, P. (2020), 'Social inequalities in health: duration of unemployment unevenly effects on the health of men and women', European Journal of Public Health, 30(2), 305-10.

Arroll, B., Khin, N. and Kerse, N. (2003), 'Screening for depression in primary care with two verbally asked questions: cross sectional study', BMJ, 327(7424), 1144-6.

Berwick, D. M., Murphy, J. M., Goldman, P. A., Ware, J. E., Barsky, A. J. and Weinstein, M. C. (1991), 'Performance of a five-item mental health screening test', Medical Care, 29(2), 169-76.

Beutel, M. E., Klein, E. M., Brähler, E., Reiner, I., Jünger, K., Michal, M., Wiltink, J., Wild, P. S., Münzel, T., Lackner, K. and Tibubos, A. N. (2017), 'Loneliness in the general population: prevalence, determinants and relations to mental health', $B M C$ Psychiatry, 17(1), 1-7.

Brown, D. W., Balluz, L. S., Ford, E. S., Giles, W. H., Strine, T. W., Moriarty, D. G., Croft, J. B. and Mokdad, A. H. (2003), 'Associations between short- and long-term unemployment and frequent mental distress among a national sample of men and women', Journal of Occupational and Environmental Medicine, 45(11), 1159-66.

Costello, E. J., Compton, S. N., Keeler, G. and Angold, A. (2003), 'Relationships between poverty and psychopathology: a natural experiment', JAMA, 290(15), 2023-9.

Davala, S., Jhabvala, R., Standing, G. and Mehta, S. K. (2015), Basic Income: A Transformative Policy for India, London: Bloomsbury.

European Social Survey ESS (2018), 'ESS9 Source Questionnaires', available at https://www.europeansocialsurvey.org/docs/round9/fieldwork/source/ESS9_source _questionnaires.pdf (accessed 12 November 2020).

Forget, E. L. (2011), 'The town with no poverty: the health effects of a Canadian guaranteed annual income field experiment', Canadian Public Policy, 37(3), 283-305.

Gibson, M., Hearty, W. and Craig, P. (2020), 'The public health effects of interventions similar to basic income: a scoping review', Lancet Public Health, 5(3), 165-76.

Hämäläinen, K., Kanninen, O., Simanainen, M. and Verho, J. (2020), Perustulokokeilun arvioinnin loppuraportti: Rekisterianalyysi työmarkkinavaikutuksista [The Final Report on the Evaluation of the Basic Income Experiment: Register Analysis on Labour Market Effects], Helsinki: VATT Institute for Economic Research, VATT Muistiot 59, available at http://urn.fi/URN:ISBN:978-952-274-259-9 (accessed 18 December 2020).

Kim, T. J. and von dem Knesebeck, O. (2016), 'Perceived job insecurity, unemployment and depressive symptoms: a systematic review and meta-analysis of prospective observational studies', International Archives of Occupational and Environmental Health, 89(4), 561-73.

Kunze, L. and Suppa, N. (2017), 'Bowling alone or bowling at all? The effect of unemployment on social participation', Journal of Economic Behavior \& Organization, $133,213-35$.

Lappalainen, K., Mattila-Holappa, P., Yli-Kaitala, K., Hult, M. and Räsänen K. (2018), 'Pisimpään työttömänä olleet käyttävät vähiten terveyspalveluja' ['Those who have been unemployed for the longest use health services the least'], Suomen lääkärilehti [Finnish Medical Journal], 42, 2421-6.

Layard, R. (2006), Happiness: Lessons from a New Science, London: Penguin Books. 
Mullainathan, S. and Shafir, E. (2013), Scarcity: Why Having Too Little Means so Much, New York: Times Books.

Paul, K. and Moser, K. (2009), 'Unemployment impairs mental health: meta-analyses', Journal of Vocational Behavior, 74(3), 264-82.

Pega, F., Liu, S. Y., Walter, S., Pabayo, R., Saith, R. and Lhachimi, S. K. (2017), 'Unconditional cash transfers for reducing poverty and vulnerabilities: effect on use of health services and health outcomes in low- and middle-income countries', Cochrane Database of Systematic Reviews, 11.

Pelzer, B., Schaffrath, S. and Vernaleken, I. (2014), 'Coping with unemployment: the impact of unemployment on mental health, personality, and social interaction skills', Work, 48(2), 289.

Ruckert, A., Huynh, C. and Labonté, R. (2018), 'Reducing health inequities: is universal basic income the way forward?' Journal of Public Health, 40(1), 3-7.

Sen, A. (1993), 'Capability and well-being', in Sen, A. and Nussbaum, M. C. (eds.), The Quality of Life, Oxford: Clarendon Press, pp. 30-52.

Troyer, A. K. and Rich, J. B. (2002), 'Psychometric properties of a new metamemory questionnaire for older adults', Journals of Gerontology, Series B, Psychological Sciences \& Social Sciences, 57(1), 19-27.

Van der Noordt, M., IJzelenberg, H., Droomers, M. and Proper, K. I. (2014), 'Health effects of employment: a systematic review of prospective studies', Occupational and Environmental Medicine, 71(10), 730-6.

Veenhoven, R. (2004), 'Subjective measures of well-being', in McGillivray, M. (ed.), Human Well-being, London: Palgrave Macmillan, pp. 214-39.

Wahrendorf, M., Hoven, H., Goldberg, M., Zins, M. and Siegrist, J. (2019), 'Adverse employment histories and health functioning: the CONSTANCES study', International Journal of Epidemiology, 48(2), 403.

Wanberg, C. R. (2012), 'The individual experience of unemployment', Annual Review of Psychology, 63, 369-96.

WHO (2001a), Basic Document, 43rd Edition, Geneva: World Health Organization.

WHO (2001b), Strengthening mental health promotion, Fact Sheet, 220, Geneva: World Health Organization.

Zuelke, A. E., Luck, T., Schroeter, M. L., Witte, A. V., Hinz, A., Engel, C., Enzenbach, C., Zacharie, S., Loeffler, M., Thiery, J., Villringer, A. and Rieder-Heller, S. G. (2018), 'The association between unemployment and depression - results from the population-based LIFE adult-study’, Journal of Affective Disorders, 235, 399-406. 